University for Business and Technology in Kosovo

UBT Knowledge Center

UBT International Conference

2016 UBT International Conference

Oct 28th, 9:00 AM - Oct 30th, 5:00 PM

\title{
Newspapers and Internet
}

Safet Zejnullahu

University for Business and Technology, safet.zejnullahu@ubt-uni.net

Follow this and additional works at: https://knowledgecenter.ubt-uni.net/conference

Part of the Social and Behavioral Sciences Commons

\section{Recommended Citation}

Zejnullahu, Safet, "Newspapers and Internet" (2016). UBT International Conference. 36.

https://knowledgecenter.ubt-uni.net/conference/2016/all-events/36

This Event is brought to you for free and open access by the Publication and Journals at UBT Knowledge Center. It has been accepted for inclusion in UBT International Conference by an authorized administrator of UBT Knowledge Center. For more information, please contact knowledge.center@ubt-uni.net. 


\title{
Newspapers and Internet
}

\author{
Safet Zejnullahu \\ UBT - Higher Education Institution, Lagjja Kalabria, 10000 p.n., \\ Prishtine, Kosovo \\ safet.zejnullahu@ubt-uni.net
}

\begin{abstract}
The paper "Newspapers and Internet" deals with the huge difference that technology has created in the approach of public toward the source of their daily information. It examines the changes that the hardcopy newspapers have experienced in order to be able to keep pace with the development of technology. Nevertheless, it deals also with, the new forms of reaching out the readers, the newspapers' future and the path they need to follow in order to controvert predictions about a total end of the printed media. Moreover, subject to the research are also the substantial changes that need to be made by newspapers, the impact of such changes to what is known as traditional journalism, the brunt that the professional journalism will bear, the efforts to save it in front of the "quick and single-source journalism", and other aspects related to the issue.

For the purpose of the study, a survey has been conducted with professionals and ordinary citizens, who were asked to tell how well they were informed about the events, the sources/medias they get information from, the reasons why they read more newspapers than news portals or the other way around. Nevertheless, subject of the survey were also why the process of buying a newspaper has been replaced by reading on their phones or other electric devices, the type of the news and the rubrics they prefer to read, the "sweet deception" they come across in the "new journalism," and other issues related to the newspapers and internet.
\end{abstract}

\section{Newspapers facing rapid growth of internet}

Radio was not removed from our lives because of television. Nevertheless, television was powerful enough to remove it from our living environments, however radio yet holds its' place in our vehicles. After the first news were released via sound and picture, an initial prediction was released, saying that the radio is going to disappear soon. Nevertheless, that prediction failed because the radios' content changed allowing the radio to become the best friend for drivers.

Also, the daily newspapers and in general the publications in paper are having the same challenge nowadays. Rapidly growing technology throughout the globe allows online media to increase their popularity in comparison to written ones. There is uncertainty and vagueness in owners of newspapers since another prediction was released that after 20 years there will be no more newspapers. Therefore, owners of newspapers are working hard, trying to keep the pace of technological growth in order for their business to stay alive. These rapid steps taken by them, sometimes seems to lower the 20 years prediction even more.

However, darkness is not everywhere. Although, there was a fear raised after the initial release of the prediction that the newspapers are going to be removed from market completely after 20 years, the 
Newspapers and Internet

newspaper owners' and journalists are rapidly researching new possible ways to stay alive just like radio did.

Amount of printed newspapers in Germany, a country with 82 Million citizens is 21 million exemplars. Steffen Grimberg, journalist in TAZ group and also media expert, after analyzing the large amount of printed newspapers in Germany, the biggest merit he gives to regional newspapers which have managed to keep their readers loyal. These kinds of newspapers make the 75 percent of the overall amount of newspapers sold in Germany. Specifically, from 21 million exemplars, only 1.5 million are sold from the classical daily newspapers. The other part is filled by tabloids, where the trending topics are the attractive ones and the ones that hold photography.

In Great Britain, we have completely another story. Since 1960s we cannot find publications with regional character anymore. Yet, there are several successful newspapers in London which sell millions of exemplars.

It is clear that the large transport expenses will be the crucial factor affecting negatively the newspapers in Great Britain. In Germany, this effect will be minor. However, how much does the internet affect medias in those countries and is there any risk from it? Obviously, the risk is quite high. Although today there are a lot of newspaper readers, either because of their profession or their habit of reading, but the challenge is how to assure that even after 20 years there will be yet newspaper readers.

Young generation of people, who were grown up having the internet as a permanent co-traveler, it is almost impossible to imagine that they will start reading printed newspapers. One of the elements which supported the newspaper removal from our lives is also their prompt action to offer newspaper for free in their online portals. Instead that this action to protect them, it was a big attacker.

Finally, it has to be clear that the journalist hard work should be paid from the reader. Consequently, this price will be much cheaper because the cost of production, transport and selling won't exist anymore. Physical transportation was the factor which lead to damage of the "Newsweek" (Its' last published newspaper was in 2012). They quit the printed version in international level because they could not handle to print and transport the newspaper. The cost was too high to be handled. Nevertheless, this conditions did not affect the "The Economist" which has not been affected by the internet yet. Therefore, each possible case should be treated in its' own way because not all the printed newspapers were not able to handle the internet impact in their daily business.

Steffen Grimbergs' opinion in regards to the above elaborated issues is that based on the fact that habits cannot be removed easily, in the next 20-30 years newspapers will still be alive. Furthermore, after this period of time, written newspapers will transform in the state that the media was in the end of $18^{\text {th }}$ and beginning of $19^{\text {th }}$ century.

\section{Hope - Good newspaper}

Qualitative newspapers are very expensive. This is a finding, which is heavy and in the meantime, it is promissory for publishers but at the same time also for professional journalist. Heavy, because in the process of searching ways to produce cheaper news, many newspapers forget the professionalism which may lead to loss of readers. Promissory, in regard to the fact that the reader may feel the need to spend a little more money in order to be well informed and therefore ask for the printed newspaper.

Jay Rosen, Professor of Journalism at the University of New York, media expert Kevin Sablan and Ryan Sholin, head of news at "Publish2", agree that the qualitative journalism is one way to save newspapers from disappearing but there are series of actions that need to be followed by producers and journalists in order to reach that goal. 
Book of Proceedings

International Conference on Social Sciences, Humanities, and other sciences

Initially, journalists should get used with the fact that newspaper can be successful, no matter in what platform the news are published. They should focus on finding topics which may be interesting for the reader and therefore it is necessary to find reliable sources, and write good and interesting news. Furthermore, the producers will have to decide about the platform and the way that will be used in order to publish the news. It may be published in newspaper, in online webpage which is a must for every newspaper nowadays, or in social media. Finally, we can reach the printed newspaper. However, having an interconnection between all these sources is essential.

Paul Bradshaw, lecturer in online journalism in Birmingham City University and media consultant, states that the newspapers should establish a friendly approach toward the readers. Nevertheless, he suggests that in the future the newspapers should consider also dealing with larger topics and maybe not being published daily. Another important element which might affect the way how people approach the newspapers might also be the content that is being offered by newspapers. If a news has been published in television, what is the reason from the newspapers to consider that news as an important news. The goal of the journalist who is an editor in the printed newspaper is to go one step further in order to be able to distinguish the news that might not be interesting for the reader. Example, if an assembly meeting is held and the television has transmitted it directly, then there is no reason for that news to be treated in details in the newspaper because it might be ignored by the readers. Instead, the newspaper should deal with what happens behind the scenes of these developments, because in most of the times it is very important for the public. Hardcopy newspapers should get closer with the readers. Even though, several years ago, the space for the reader comments has been removed, nowadays several newspapers are allowing only important personalities to publish their opinion. Yet, this is not a good approach. One positive step for journals might be the classic sections which are preferred by a lot of users. In addition, having one reportage, one feuilleton, one long conversation with an important person might still be interesting for the readers.

\subsection{News for „the unknown“ and news for „the known“}

Let's discuss the news 15 years earlier. In that period of time, you could buy a newspaper and start reading it in the morning, while having a coffee or watching the news at home. Generally, at that time you could start reading the newspaper with a title: "President Rugova declared..."; "Head of UNMIK expressed that..."; "What law was approved yesterday.". Furthermore, a section for the black column, a couple of news from economy and the world, sport section, crossword space, advertisement part and finally memorial for dead people.

Generally, the goal of the newspaper was to fulfill the requirements of the people which were seeking to learn what has happened in the previous day, or in other word what the editors have decided to inform today. There were only a few sections that you could find somebody you knew personally. One pensioner, the only persons who could recognize the ones that are in the memorial section. Nowadays, social networks and other online medias provide us much more opportunities. Therefore, not many persons today open the Facebook at the morning in order to check the news regarding politics, what laws are approved today, or what is happening in Siria or Ukraine. Respectively, most of the persons tend to open their Facebook profiles in order to check out where his/her relatives have been last night, at what coffee shop they have been and with whom. Nevertheless, the Facebook becomes much more attractive because it offers to us news regarding our family, friends, relatives and/or our interests, instead of providing information about topics that we might not be interested in. 


\section{Why online media are leading}

Online media took the lead in comparison with hardcopy newspapers very rapidly for many practical issues. They can be accessed from anywhere and at any time. At the moments when we only had internet connection in our computes, the hard-copy newspapers didn't feel the risk of being the secondary choice of readers. Nevertheless, with the new technological advancements, the internet connection is everywhere and therefore the news are everywhere.

The initial attempts of newspapers seemed to be desperate for them. Newspapers lost millions of euros while trying to keep their readers. In this process, their biggest step was taken in a wrong way, while including in their online web page their newspaper. Therefore, the reader considered the hard copy newspaper as worthless and likewise their motivation to buy the newspaper was dropped. Nevertheless, even though some newspapers decided not to go in the online form, they were affected in a negative manner by the other newspapers' decisions.

Online media became very attractive and acceptable for the end user since the news were provided in a much faster way. In addition, offering the possibility of interactivity, allowed the online media to get closer to the reader in comparison with radio and television which up to that time couldn't afford the interactivity. Jim Hall, in the book "Online journalism" published in 2001, mentions the length of the news, ability to adopt to the customer needs, various opportunities and interactivity, as crucial elements that allowed online media to become very attractive and leader. Nevertheless, he considers the interactivity to be equal with the basic elements of journalism - correctness, objectivity and the truth. What do we mean with interactivity? Giving the control to the end user.

Crucial elements which are positive in regard to online media are the availability of text, photo and video. Nevertheless, also allowing the end user to choose what he/she wants to read/see is a big indicator. Therefore, the reader feels that he/she has control over the medium which offers the news. In case a news is fragmented in several video pieces, the reader will have the opportunity to choose what they want to see/read. However, in television this is not possible yet. You would be forced to watch a TV show for a specific amount of time but you won't be allowed to interact and chose what you want to see.

While using online media, the reader is not dependent on a single source, instead they are able to browse through various online media and gather the needed information. In the other hand, while getting informed through newspapers, the reader is forced to buy every single source that they want to read. What does this mean for journalists in online media? Simple as that - put the control under the readers' hand. Control in the aspect of time and space to consume the news. To allow content distribution through social media and in the meantime, provide news to the reader through their desired channels (e.g. e-mail, SMS etc.).

Online medias have made the reader part of the news; therefore, it consists one of the reasons for their success. Not rarely, the reader is asked from online media to send its' content and be part of the news creation. Finally, the reader has its' commenting part in order to extend and fulfill the news with all the necessary and new details.

Often, online media offers the possibility for the reader to send their questions in regard to a specific person, whereas the interview will only be based on those questions. Even though, there are many advantages offered by the technology for the online media, there are still some issue, mostly professional which sometimes put doubt in the professionalism of journalism in the content of their news.

Rushing to provide the news in the fastest possible way, without even verifying it, often creates invidious situations for organizations attempting to reach a professional level of journalism. Even though in journalism it is as a basic rule for the news to contain both sides, speed and professionalism, 


\section{Book of Proceedings}

International Conference on Social Sciences, Humanities, and other sciences

but for online media this border is almost broken. Write the first part, its' posture, ensure readings and clicks, then take the posture of the other part, and ensure readings and clicks again. This represents a high level of risk. Many journalists have as a justification the fact that there are millions of readers that in every minute are waiting for the news to be provided, therefore there isn't enough time to wait until the posture of the other side is taken. While, sometimes this may be tricky, because the audience which tend to receive a full news of above average quality get disappointed of this approach and therefore feel not appreciated.

Moreover, the possibility to provide more photos than in a newspaper and also provide a video next to the news, which is impossible to be done in a newspaper holds in itself small elements risk. The risk gets higher at the moment when photo and video which are used by online media go beyond the acceptable borders. Having a remark of " +18 " or notice of disruptive content in the photo and/or video sometimes resulted to be nonprotective for the reader, who is not a target audience, but yet its' attracted by the content, especially for persons under that age who tend to check what is that content that they are not allowed to see.

Also, parents who may want to control their kids home PC, they can do it but yet it is hardly managed to control his/her phone and/or other accessible devices outside home environment $\mathrm{x}$.

\section{They have large audience but are not professional...}

In such a small market like Kosovo, it was obvious that the online media would take the lead in comparison with newspapers. Some newspapers gave up immediately at the first appearance of online media, and started to create their own online content while some newspapers decided later on to proceed with both versions, hardcopy, online and also in their social medias. This kind of act is contributed by the readers' attitude to read news in the internet but also from the fact that online media is cheaper than the printed media. The time of online media creation was not a good time for the hardcopy newspapers, which were trying to survive. Fighting for survival came as a result of the number of sold copies of newspapers per day in comparison with ten years before. At that time, the revenue for newspapers was generated by the advertisements mainly done by the governmental institutions, which lead to better income for newspapers and affected directly the quality of the news. When the governmental institutions started to use other ways of advertising, the newspapers started to use various ways to reduce costs, by reducing staff number and also focus on online media format. In some cases, newspapers remain alive because their owners finance them by the profit generated in other businesses. One crucial element which can be noticed in the newspapers in Kosovo is that they didn't try to follow the readers' requirements neither obtain new readers. While online portals are a story in its' own in Kosovo. Firstly, they managed to function without being affected by the legal limitations. Until we had the decision of the European Court that makes the online media responsible for every readers' comment, the most attractive part for the readers were comments part. Basically, there were no limitations, and you could blame and tag everyone. Nevertheless, at the moment that comments seemed to be a risk, an interconnection between Facebook and online media showed up and therefore kept available the possibility for the reader to express himself or herself.

There are just a few cases, in order not to say any, that the online media tried to establish connection with the reader, to make him part of the news and/or content. It seemed acceptable for both sides, editors to create news with links and the readers to be able to blame at anyone in anytime no matter what the news contain. There are many cases when we have a news which is sport related but comments placed for religion, politics, corruption or prostitutions can contain $90 \%$ of all comments. 
Newspapers and Internet

Lack of credible sources and news balance, while presenting at least two parts, are social media elements which are hopefully going to be developed further. Nowadays, it is like a trend to steal news from other sources. Moreover, it is quite understandable and acceptable in Kosovo, to find a mistake in the news tittle and then see the same mistake in every portals' page. Basically, a disrespect toward the reader.

\subsection{What is the readers' interest and on what do they rely in Kosovo?}

A survey from the author included 100 citizens of various ages, genders, and their professional ability, and gave a clear view of the readers of traditional and modern media, together with the rate of readings and trust that readers have for each of them.

Initially, 30 percent of the readers who were part of the survey were of 20-30 years old, while 20 percent were of 30-40 years old and lastly 27 percent were above 40 years old. Regarding the gender, 54 percent were females and 46 percent were male. 65 percent of them were university graduates, and $35 \%$ have completed only high school. Among them, 68 percent live in the city while 32 percent live in villages. Results of the survey show that even though citizens have a quite high level of education they are still not satisfied with the quality and quantity of latest information that they receive.

In the question "Are you completely informed about the latest news within and outside the country in all fields of life?" only 62 persons have responded with "Yes" while 38 persons responded with "No". This fact is not good for medias but in the other hand it is a hope for them to get new readers. There are many uninformed readers but medias should find the right approach in order to create the proper news which would be interesting for the possible reader. However, when analyzing the source of the information, in the last years the internet has become the main source of the information.

Moreover, in the question "What is the source of your daily information?" 60 persons have mentioned the internet, 20 have mentioned television and only 5 persons have stated that they get daily information from radio. Having the internet as a leader, it is quite understandable because it is a major trend in the whole world. One the issues which is to be concerned in Kosovo, is the fact that the newspapers lost the fight very easily in regard to keeping the readers. This is expressed based on the answers that are received from the following question: "Where do we find more professional news?", where 70 percent of the people part of the survey said that the printed newspapers are more professional in comparison with 30 percent that this attribute dedicate to the online portals.

And while we are discussing the habit of buying newspapers, the survey has shown that people between 30 and 40 years old are the ones who buy newspapers with a rate of 57 percent stating that they buy newspapers in comparison with 43 who do not.

Moreover, in the question "How often do you buy newspapers?" there is relatively smaller percentage of people who keep being informed by newspapers. 26 percent of people stated that they buy newspapers "Every day", 15 percent stated "Once per week", 24 percent stated "Rarely" while 35 percent of people stated that they "never" buy newspapers.

Very interesting are the answers that are gathered from the question "Why do people read in the online portals?". 52 percent of the people who find the online portals as their main source of information answered that "they find correct information in online portals", while 31 percent stated that "they find attractive information. Nevertheless, 7 percent of people stated that "online portals are faster that newspapers", 6 percent of them stated that "they publish verified information" and lastly 4 percent of people simply read the portals in order to have a general view of latest developments.

The other part of the survey shows the audience opinion in regard to the most interesting sections for them: politics have the lead with 42 percent, followed by sport section with 12 percent, entertainment 
Book of Proceedings

International Conference on Social Sciences, Humanities, and other sciences

holds 8 percent, crimes section holds 8 percent also, sections from economics have 8 percent, show business holds 8 percent, 2 percent only go for the technology and the same goes for science.

Another interesting statistic achieved from the survey is that only 24 percent of the readers' access directly into the portal, instead 76 percent of people noted that they access the portal and newspaper accounts in Facebook.

Nevertheless, the answers of the last question in the survey should be very stressful for portals and their way of approaching the readers. In the question "Do you get disappointed when behind a very interesting title, there is nothing interesting?", 87 percent of the people stated "Yes" while only 13 percent of them stated that it doesn't impress them.
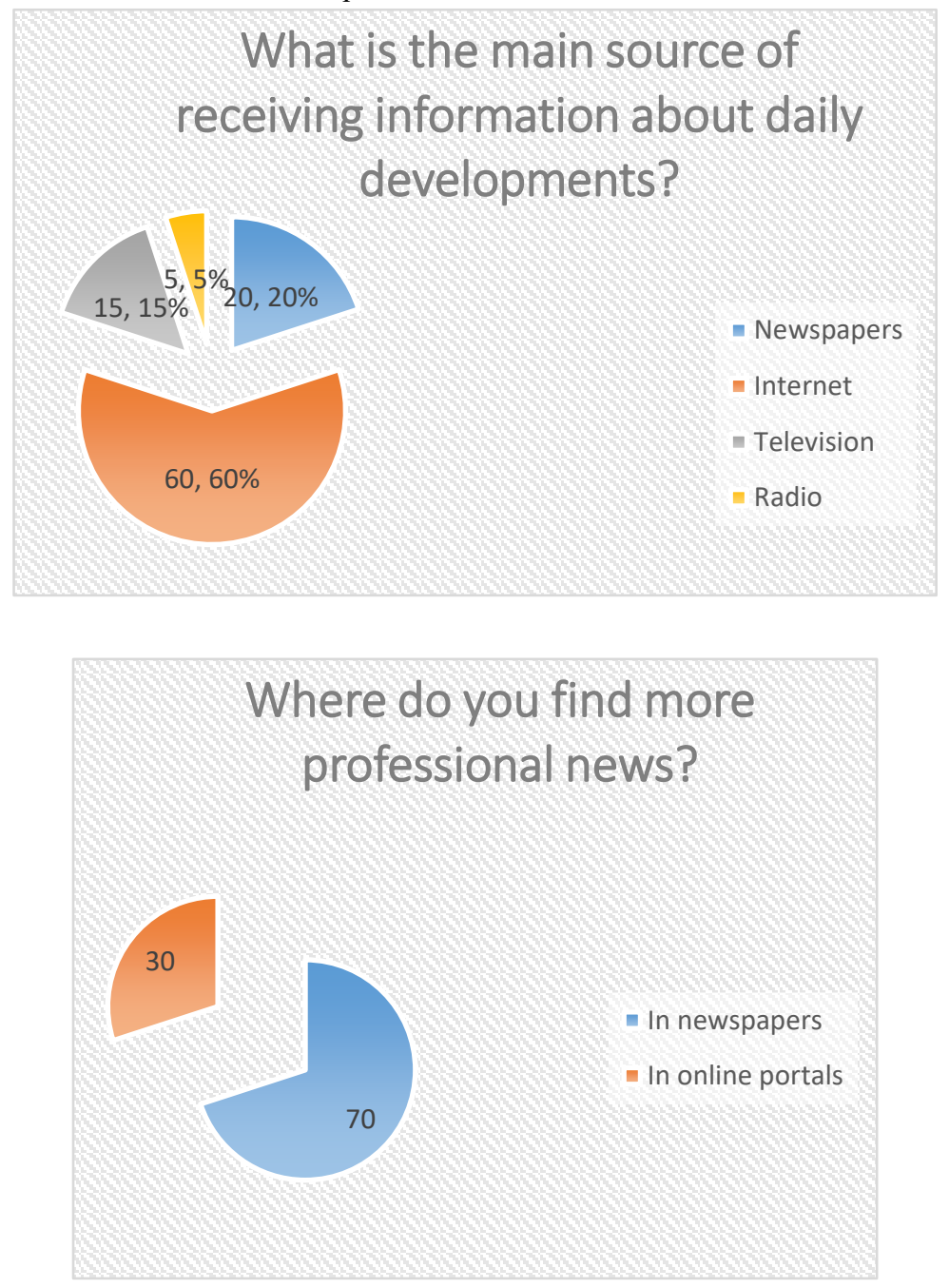


\section{Challenges of the future: How to teach the young generation of "internet era" to read newspapers?}

In printed newspapers or online portals, a big journalism challenge today and in the future, is how to urge the new generation of people to read news. A generation that never bought a newspaper, except when someone from their family asked them to buy a newspaper together with the bread. The generation which is grown with the internet and are not familiar with reading something outside the social medias, or music and entertainment sections.

In Kosovo, several groups of different ages remain not a target of newspaper focus. What do daily newspapers offer for kids, high scholars and students? Except some short sections which are focused in show business, online media have won the fight because of their bigger possibilities in comparison with daily newspapers because they didn't put any effort into putting content in daily newspapers for young people.

Political development, corruptive affairs and almost orange news, with the portraits of four to five state leaders which hold the main page of the newspaper are not attractive for the young age people. While the middle generation of people and those older than sixty years keep reading the newspapers because of their old habits and therefore based on statistics they are minority in comparison with more than half of the population who are younger than 30 years old.

While we are not seeing effort from newspapers side, how we can expect to see result. In order to save the number of newspapers being sold, the newspapers need to make an immediate move into integrating within newspapers, news for every generation of readers.

A short and meaningful title is always better in comparison with a long title for all type of readers. A larger photo with better quality is always more attractive than the actual photos which most of the time are small and non-qualitative. Moreover, a high school student won't buy the newspaper in case he/she finds always in the first page of newspaper, photos of presidents, prime minister or ministers, no matter how important the topics might be. Instead, he prefers to see in the first page someone similar to him, because only like that he nay feel the news as important for him.

Briefly, newspapers should move toward researching the needs and interests of the readers. Daily magazines, with short news with large pictures might be a good selection for the future. In the other hand, a research has shown that even students of journalism have difficulties in remembering the last three events of the last week, which leads to the conclusion that also the online media are not doing enough to inform the audience enough and in the proper way.

Titles holding cheating content, mainly inappropriate picture, lack of proper sources and citations inside a text in most of the cases are not wanted by the readers. With such elements, which are part of every online portal in Kosovo, their main target is reaching as many clicks as possible in the shortest possible time, instead of focusing in informing and keeping the readers of all generations as reliable to them. Therefore, professionalism of portals is necessary. This process will remove from the competition the portals which are functioning with only one employee, with a few advertisements and news "borrowed" from other portals. While reality reflects that in order to have a proper online portal, the online portal must have a larger editorial office than daily newspapers. Otherwise, they will become unattractive for the readers. 
Book of Proceedings

International Conference on Social Sciences, Humanities, and other sciences

\section{Conclusion}

Developments in the modern journalism, affected by the technology developments, gradually have removed the term "qualitative journalism" from the market, therefore allowing space for "good journalism" which seems to be more than enough in order the fulfill the audience requirements.

Good journalism, informs and makes analysis, comments but at the same time, it entertains. These are the elements that should be covered as soon as possible from daily printed newspapers and online medias in order to be successful.

The future is reserved for the online medias, but filtered based on the quality and profiling which follow the tremendous requests which are rapidly changing from the audience. In this competition, should be involved also the newspapers in order not to disappear from the market by following the reader interest and requirements by becoming different and more attractive. In order for newspaper to be able to survive also after 20 years, they must find the way to fulfill the needs also of the young generation of people which are used to get informed only via internet. If television didn't destroy radio, but instead it transformed it, also the online media won't destroy newspapers. Instead they will transform them.

\section{References:}

1. Survey realized by the author, September 2016;

2. Delfi AS v. Estonia: Grand Chamber confirms liability of online news portal for offensive comments posted by its readers (https://strasbourgobservers.com);

3. Steffen Grimberg: "Local and regional press resists crisis" (http://www.media.ba);

4. "After 79 years in print, Newsweek goes digital only" (http://www.reuters.com), 18 October 2012;

5. Kevin Sablan \& Ryan Sholin: "12 Things Newspapers Should Do to Survive" (http://mashable.com);

6. Jim Hall: "Online journalism" (2001), parts published in "BASIC principles of online journalism: I is for Interactivity”. 